\title{
Lettuce chlorosis virus P23 Suppresses RNA Silencing and Induces Local Necrosis with Increased Severity at Raised Temperatures
}

\author{
Kenji Kubota and James C. K. Ng
}

First author: NARO Agricultural Research Center, Kannondai, Tsukuba, Ibaraki 305-8666, Japan, and Department of Plant Pathology and Microbiology, University of California, Riverside 92521; second author: Department of Plant Pathology and Microbiology, University of California, Riverside 92521

Accepted for publication 19 January 2016.

\begin{abstract}
Kubota, K., and Ng, J. C. K. 2016. Lettuce chlorosis virus $\mathrm{P} 23$ suppresses RNA silencing and induces local necrosis with increased severity at raised temperatures. Phytopathology 106:653-662.

RNA silencing functions as an antivirus defense strategy in plants, one that plant viruses counter by producing viral suppressors of RNA silencing (VSRs). VSRs have been identified in three members of the genus Crinivirus but they do not all share identical suppression mechanisms. Here, we used Agrobacterium co-infiltration assays to investigate the suppressor activity of proteins encoded by Lettuce chlorosis virus (LCV). Of 7 LCV proteins (1b, P23, HSP70 homolog, P60, CP, CPm, and P27) tested for the suppression of silencing of green fluorescent protein (GFP)

expression in wild-type Nicotiana benthamiana plants, only P23 suppressed the onset of local silencing. Small-interfering (si)RNA accumulation was reduced in leaves co-infiltrated with $\mathrm{P} 23$, suggesting that $\mathrm{P} 23$ inhibited the accumulation or enhanced the degradation of siRNA. P23 also inhibited the cell-to-cell and systemic movement of RNA silencing in GFPexpressing transgenic $N$. benthamiana plants. Expression of P23 via agroinfiltration of $N$. benthamiana leaves induced local necrosis that increased in severity at elevated temperatures, a novelty given that a direct temperature effect on necrosis severity has not been reported for the other crinivirus VSRs. These results further affirm the sophistication of crinivirus VSRs in mediating the evasion of host's antiviral defenses and in symptom modulation.
\end{abstract}

Lettuce chlorosis virus (LCV), a member of the genus Crinivirus (family Closteroviridae) and disease causal agent of lettuce (Lactuca sativa) plants of all types, has been prevalent in the American Southwest since the 1990s (Duffus et al. 1996). A recent study reporting the occurrence of LCV in green bean (Phaseolus vulgaris) plants in Spain suggests that the virus is emerging in new geographic areas and broadening its host range (Ruiz et al. 2014). Transmission by whiteflies (family Aleyrodidae) is a key driver of the rapid and global spread of criniviruses (the generic name for viruses in the genus Crinivirus). In the case of LCV, transmission is achieved by specific whitefly vectors of the Bemisia tabaci species complex (Chen et al. 2011; De Barro et al. 2011; Ng 2013; Ng and Zhou 2015).

As with all criniviruses and closteroviruses (the generic name for viruses in the genus Closterovirus, the type genus of the family Closteroviridae), LCV belongs to the alpha-like supergroup of positive sense (+), single stranded (ss) RNA viruses. The bipartite genome of LCV is 8,591 (RNA 1) and 8,569 (RNA 2) nucleotides (nt) long (Salem et al. 2009). LCV RNA 1 contains four open reading frames (ORFs): 1a, 1b, P8, and P23; while LCV RNA 2 contains 10 ORFs: P5.6, P6, heat shock protein 70 homolog (HSP70h), P6.4, P60, P9, CP (major coat protein), CPm (minor coat protein), P27, and P4.8 (Fig. 1). The genome of LCV and that of other criniviruses and closteroviruses share signature similarities, but they also exhibit a considerable level of diversity, which is reflected in the genome structure and coding capacity of the different members (Kiss et al. 2013). Based on sequence analyses and comparative inferences with Lettuce infectious yellows virus (LIYV; the type species of Crinivirus) and closteroviruses, the LCV RNA 1 encoded ORF $1 \mathrm{a}$ and $1 \mathrm{~b}$ proteins are likely translated directly to produce an independent replication module consisting of

Corresponding author: J. C. K. Ng; E-mail address: jamesng@ucr.edu

http://dx.doi.org/10.1094/PHYTO-09-15-0219-R

(c) 2016 The American Phytopathological Society a papain-like leader protease (P-PRO), methyltransferase (MTR) and helicase (HEL), and an RNA-dependent RNA polymerase (RdRp), respectively (Karasev 2000; Salem et al. 2009). Consequently, RNA 1 is capable of replication on its own (Mongkolsiriwattana et al. 2011). RNA 2, which contains no known replication-related ORFs, replicates using the RNA 1-encoded replication-associated proteins supplied in trans (Mongkolsiriwattana et al. 2011). LCV, as with other ss(+)-RNA viruses, synthesizes complementary minus-strand $(-)$-RNAs and uses them as templates for the production and propagation of genomic (g) (+)-RNAs and subgenomic (sg) RNAs (Mongkolsiriwattana et al. 2011; Nagy and Pogany 2012).

Production of the double-stranded (ds) [(+)- and (-)-strand] replicative form of viral RNA can trigger RNA silencing, a sequencespecific RNA degradation machinery that functions in antivirus defense and gene regulation in a wide array of eukaryotic organisms ranging from animals to plants (Ding and Voinnet 2007; Pumplin and Voinnet 2013). The mechanism triggering defensive RNA silencing against viruses is well understood, and involves the processing of viral dsRNAs, such as the replication intermediate of single-stranded RNA viruses described above or ssRNAs with significant intramolecular base paired regions, into small-interfering (si)RNAs by specific cellular enzymes that possess dsRNase activity. Subsequently, the siRNAs serve as guides for the cleavage of homologous ssRNA molecules in an RNA-induced silencing effector complex (Baumberger and Baulcombe 2005; Liu et al. 2004; Meister and Tuschl 2004). One key feature of RNA silencing in plants is that it is not only induced locally in infected cells, but it also spreads cell-tocell and systemically (Himber et al. 2003; Palauqui et al. 1997; Parent et al. 2012; Voinnet 2005; Voinnet et al. 1998). As the silencing signal spreads via cell-to-cell and systemic movement, it facilitates host defense to prevent further spreading of the virus (Ding and Voinnet 2007; Pumplin and Voinnet 2013; Schwach et al. 2005). To counteract the RNA silencing-mediated antiviral defense, many plant viruses encode viral suppressors of RNA silencing (VSRs) in their genomes. Although the mode of suppression varies 
for different VSRs (Burgyán and Havelda 2011; Diaz-Pendon and Ding 2008), it is clear that the balance between RNA silencing and VSR activities is crucial in influencing successful infection and symptom development (Brigneti et al. 1998; Kasschau and Carrington 1998; Kubota et al. 2003; Voinnet et al. 1999).

VSRs have been identified in three crinivirus species: Sweet potato chlorotic stunt virus (SPCSV), Tomato chlorosis virus (ToCV), and Curcurbit yellow stunting disorder virus (CYSDV). However, the suppression mechanisms differ among them. In SPCSV, the RNA 1-encoded P22 suppresses local, cell-to-cell, and systemic silencing induced by dsRNA, and induces chlorosis and necrosis in the agroinfiltrated tissues (Kreuze et al. 2005). The SPCSV RNA 1-encoded RNase III also exhibits suppressor activity in planta and, when tested in vitro, degrades synthetic ds siRNAs into shorter (14 base pairs) dsRNAs (Cuellar et al. 2009). ToCV encodes three VSRs: P22, encoded by RNA 1, and CP and CPm, both encoded by RNA 2 (Cañizares et al. 2008). ToCV P22 is a strong suppressor of local silencing and is effective for a long period but can neither suppress cell-to-cell nor systemic silencing (Cañizares et al. 2008). The ToCV

\section{A}

\section{LCV RNA1}

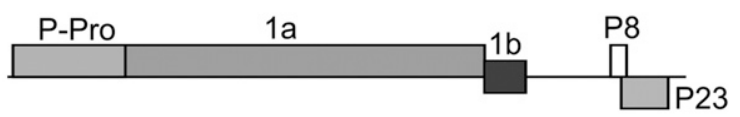

\section{LCV RNA2}

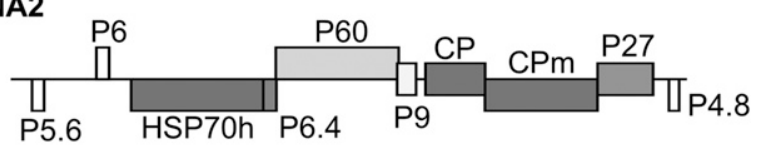

B

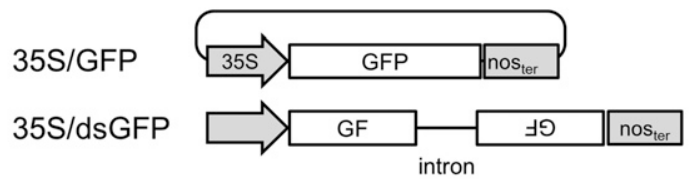

LCV constructs
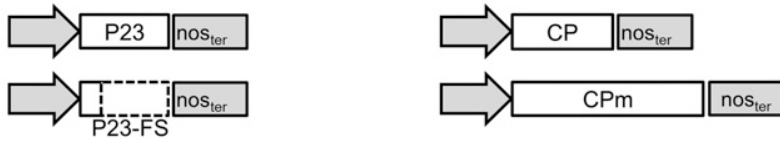

empty vector

TuMV P1/HC-Pro
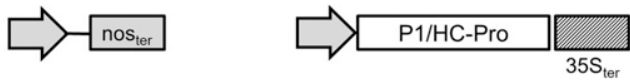

Fig. 1. Genome organization of Lettuce chlorosis virus (LCV) and the LCV genes tested for their role in silencing suppression. A, Schematic representation of the bipartite genome of LCV. The open reading frames (ORFs), shown as rectangles, encode the following: P-Pro, protein with a papain-like proteinase domain; 1a, protein containing a methyltransferase and a helicase domain; 1b, RNA-dependent RNA polymerase; HSP70h, heat shock protein 70 homolog; CP, major coat protein; CPm, minor coat protein. The other ORFs are given numerical identifiers preceded by the letter ' $\mathrm{P}$ ', with numbers corresponding to the relative molecular masses of the encoded proteins. B, The binary vector constructs used for silencing suppression assays. These include the binary vector alone (empty vector) and binary vectors engineered to express: P1/HC-Pro of Turnip mosaic virus (TuMV P1/HC-Pro), green fluorescent protein (GFP) (35S/ GFP), dsGFP (35S/dsGFP; engineered to produce GFP hairpin dsRNA), LCV P23, and P23-FS (a frameshift mutant of LCV P23; dash-bordered box). The binary vectors all contained the Cauliflower mosaic virus $35 \mathrm{~S}$ transcript promoter $(35 \mathrm{~S}$; gray arrow) and the nos terminator (nos ter $_{\text {; }}$ gray box), except for TuMV P1/HC-Pro which contains the $35 \mathrm{~S}$ terminator $\left(35 \mathrm{~S}_{\mathrm{ter}}\right.$; hatched box).
$\mathrm{CP}$ interacts with a Nicotiana benthamiana protein homolog of $S$-adenosyl homocysteine hydrolase (SAHH) in $N$. tabacum to enhance local silencing (Cañizares et al. 2008, 2013). The VSR mechanism of ToCV CPm is unknown. CYSDV P25 suppresses local silencing induced by both ss (sense) RNA and dsRNA. However, CYSDV P25 does not suppress cell-to-cell movement of the silencing signal, and its suppression activity on systemic silencing is unknown (Kataya et al. 2009). The diverse modes of action of crinivirus suppressors and the rapid global spread of these viruses underscores the importance of identifying and characterizing the VSRs of other newly emerging criniviruses.

In this study, we used Agrobacterium co-infiltration leaf patch assays to test seven proteins expressed from LCV RNAs 1 and 2 to determine if they had VSR activity against silencing of green fluorescent protein (GFP) expression in wild-type (WT) N. benthamiana plants, and in $N$. benthamiana plants transgenic for the GFP gene. Our results show that LCV P23 functions as a VSR by suppressing the onset of local silencing and inhibits the cell-to-cell as well as systemic movement of the silencing signal. In addition, we show that P23, delivered alone to $N$. benthamiana leaves by agroinfiltration, induces local necrosis that increases in severity at higher incubation temperatures. A temperature effect on necrosis severity has hitherto never been reported for any crinivirus VSRs. The role of LCV P23 in RNA silencing suppression and plant host innate immunity and symptom development is discussed.

\section{MATERIALS AND METHODS}

Construction of binary vectors. $\mathrm{pHC}$-Pro (referred to as the Turnip mosaic virus [TuMV] P1/HC-Pro construct) is a binary plasmid (Chen et al. 2012) that contains the cDNA corresponding to the 5'-untranslated region (UTR) of the Tobacco etch virus (TEV) genomic RNA (with a 144-bp translational enhancer [TE]) followed by the TuMV P1/HC-Pro coding sequence. Specific expression of TuMV P1/HC-Pro is driven by the Cauliflower mosaic virus (CaMV) $35 \mathrm{~S}$ promoter (engineered upstream of the TEV 5' UTR) and the $35 \mathrm{~S}$ terminator (engineered downstream of the P1/HC-Pro gene sequence).

The $35 \mathrm{~S}$ promoter-mGFP5ER-Nos terminator region was PCRamplified with oligo primer pairs mgfp5ER-upper and SmaI-mgfp5ERlower (Table 1) using the genomic DNA of GFP transgenic $N$. benthamiana line $16 \mathrm{c}$ plants as template. Extraction of plant genomic DNA was performed essentially as described previously (Dellaporta et al. 1983). The PCR product was digested with HindIII and SmaI and cloned into the HindIII and SacI (blunted by fill-in reactions) digested sites of the pCB301 binary vector (Xiang et al. 1999), which yielded pCB-mGFP5-ER (referred to as the 35S/GFP construct). To produce the hairpin construct of GFP, a 270-bp intron sequence of the $N$. benthamiana phytoene desaturase gene (Ruiz et al. 1998) was PCR-amplified with oligo primer pairs BstZ17INbPDS-1444fw and SacSpeSma-NbPDS-1490rv (Table 1) by using the $N$. benthamiana genomic DNA as template. The BstZ17I-SacI fragment of pCB-mGFP5-ER (corresponding to nt 533 at the $3^{\prime}$ end of the mGFP5-ER sequence) was replaced with the PDS intron fragment digested with the same enzymes to yield the intermediate plasmid pCB-mGFP5-Int. The XbaI-BstZ17I fragment of pCBmGFP5-ER (corresponding to the 5' end at nt 533 of the mGFP5-ER sequence) was inserted into SmaI-SpeI site of pCB-mGFP5-Int to produce pCB-mGFP5-IR (referred to as the 35S/dsGFP construct).

The cloned infectious cDNAs of LCV RNAs 1 and 2 (pCM1 and pCM2, respectively) (Mongkolsiriwattana et al. 2011) were used as templates for PCR amplification of the LCV 1b, P23, HSP70h, P60, $\mathrm{CP}, \mathrm{CPm}$, and P27 coding sequences used for making the binary constructs that express the respective proteins upon infiltration of the transformed Agrobacterium tumefaciens in leaves of $N$. benthamiana plants. PCR amplifications were performed with the following oligo primer pairs: 1b-fw and 1b-rv; P23-fw and P23-rv; HSP70h-fw and HSP70h-rv; P60-fw and P60-rv; CP-fw and CP-rv; CPm-fw 
and CPm-rv; and P27-fw and P27-rv (Table 1). The PCR-amplified products were each subcloned into the pGEM-T Easy vector (Promega). Subsequently, the cloned CP fragment was excised by BamHI and SacI digestion and cloned into the cognate sites of pCB-mGFP5ER, which yielded the recombinant binary vector pCBLCV CP. To generate an empty vector, pCB-Empty, the CP sequence from $\mathrm{pCB}-\mathrm{LCV} \mathrm{CP}$ was removed by restriction digestion with $\mathrm{Xba \textrm {I }}$ and SpeI, followed by ligating the digested ends of the vector backbone with T4 ligase.

The TEV TE of pHC-Pro was inserted into the XbaI site of pCBLCV CP. Specifically, to introduce the TEV TE into pCB-LCV CP, the TEV TE of pHC-Pro was amplified with oligo primer pairs TEV5'UTR-1fw and TEV5'UTR-144rv (Table1), digested with

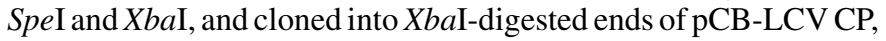

TABLE 1. Oligonucleotide primers used for the construction of the binary vectors of Lettuce chlorosis virus (LCV)-encoded proteins

\begin{tabular}{lc}
\hline Primer & Sequence $\left(5^{\prime}-3^{\prime}\right)$ \\
\hline mgfp5ER-upper & CAGCTATGACCATGATTACGCC \\
SmaI-mgfp5ER-lower & ATATCCCGGGAATTCCCGATCTAGTAACATAGATGA
\end{tabular}

BstZ17I-NbPDS-1444fw

GCGCGTATACTCCTGTGATAAATGTCCATATATG

SacSpeSma-NbPDS-1490rv

GCGAGCTCACTAGTTTTccegggTGTTCTTCAGTTTTCTGTCAAAC

$1 b-f w$

GCGGATCCAACATGAGCATATATAATCTCCGCATTG

1b-rv

GCGAGCTCTTACACATTCACACTGAATCTTT

P23-fw

GCGGATCCAACATGTCGTCTCATCGTATACCTT

P23-rv

HSP70h-fw

HSP70h-rv

P60-fw

P60-rv

CP-fw

CP-rv

CPm-fw

CPm-rv

P27-fw

P27-rv

TEV5'UTR-1fw

TEV5'UTR-144rv
GCGAGCTCTTAAGAAAATGTGAGCCAGTCTA

GCGGATCCAACATGGCAGCTAAGGCAGGG

GCACTAGTTCATTTATTCTTAAAATTTTTGTTCAA

GCTCTAGAAACATGGTGAGTCTAAAAAATAGCTCC

GCACTAGTTCAATTTCGTAAGATCCATGTAT

GCGGATCCAACATGGGTGATAGCAAAGAAACA

GCGAGCTCACTAGT $\underline{\text { TTATTTACTGCAACCCCCTG }}$

GCGGATCCAACATGGATAGAGAGGATTTTTATGAAG

GCACTAGTTTAGTACAACTGATTCACATTTACAAT

GCGGATCCAACATGTCGAACATGGAAGTTG

GCACTAGTTTAAAAATTTTTTAATGGTTTGATC

AGTACTAGTACCTCGAgaattcTCAACAC

AGATCTAGAGGCTATCGTTCGTAAATGG

\section{Description}

Nucleotides corresponding to the upstream sequence of the $35 \mathrm{~S}$ promoter-mGFP5ER-Nos terminator region of Nicotiana benthamiana line 16c

A SmaI restriction site (bold) and nucleotides complementary to downstream sequence of the 35S promoter-mGFP5ER-Nos terminator region of $N$. benthamiana line $16 \mathrm{c}$

A BstZ17I restriction site (bold) and nucleotides corresponding to the $N$. benthamiana phytoene desaturase gene mRNA (EU16535) position 1444 to 1467

SacI (bold), SpeI (italic) and SmaI (lower case) restriction sites and nucleotides complementary to the $N$. benthamiana phytoene desaturase gene mRNA (EU16535) position 1468 to 1490 (underlined)

A BamHI restriction site (bold), an additional start codon (italic) and nucleotides corresponding to those of LCV RNA 1 position 6044 to 6065 (underlined)

A $S a c$ I restriction site (bold) and nucleotides complementary to those of LCV RNA 1 position 7561 to 7539 (underlined)

A BamHI restriction site (bold) and nucleotides corresponding to those of LCV RNA 1 position 7772 to 7793 (underlined)

A $S a c$ I restriction site (bold) and nucleotides complementary to those of LCV RNA 1 position 8343 to 8365 (underlined)

A Bam $\mathrm{HI}$ restriction site (bold) and nucleotides corresponding to those of LCV RNA 1 position 1526 to 1543 (underlined)

A SpeI restriction site (bold) and nucleotides complementary to those of LCV RNA 2 position 3170 to 3196 (underlined)

A $X b a I$ restriction site (bold) and nucleotides corresponding to those of LCV RNA 2 position 3355 to 3378 (underlined)

A SpeI restriction site (bold) and nucleotides complementary to those of LCV RNA 2 position 4886 to 4908 (underlined)

A BamHI restriction site (bold) and nucleotides corresponding to those of LCV RNA 2 position 5250 to 5270 (underlined)

SacI (bold) and SpeI (italic) restriction sites and nucleotides complementary to those of LCV RNA 2 position 5983 to 6002 (underlined)

A BamHI restriction site (bold) and nucleotides corresponding to those of LCV RNA 2 position 6002 to 6026 (underlined)

A SpeI restriction site (bold) and nucleotides complementary to those of LCV RNA 2 position 7400 to 7426 (underlined)

A BamHI restriction site (bold) and nucleotides corresponding to those of LCV RNA 2 position 7428 to 7446 (underlined)

A SpeI restriction site (bold) and nucleotides complementary to those of LCV RNA 2 position 8105 to 8129 (underlined)

SpeI (bold), XhoI (italic) and EcoRI (lower case) restriction sites and nucleotides corresponding to those of TEV RNA position 12 to 20 (underlined)

A $X b a \mathrm{I}$ restriction site (bold) and nucleotides complementary to those of TEV RNA position 126 to 143 (underlined) 
which yielded pCBT-LCV CP. To construct the binary vectors for expressing LCV proteins 1b, P23, HSP70h, P60, CPm, and P27, the recombinant $\mathrm{pGEM}-\mathrm{T}$ Easy vectors that contained the respective LCV gene sequences were digested with the appropriate restriction enzymes BamHI (or XbaI) and SpeI (or SacI). Each of the excised products was used to replace the $\mathrm{CP}$ gene sequence previously

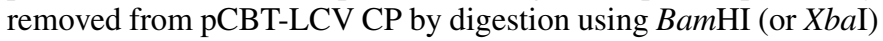
and $\mathrm{SacI}$ (or SpeI). This procedure yielded the following recombinant binary vectors: pCBT-LCV 1b, pCBT-LCV P23, pCBT-LCV HSP70h, pCBT-LCV P60, pCBT-LCV CPm, and pCBT-LCV P27. pCBT-P23-FS, a binary vector that expresses a frameshift mutant of LCV P23, was generated by digesting pCBT-LCV P23 with SpeI (located in the $\mathrm{P} 23$ coding region), and blunting the restriction site by filling-in reactions. These recombinant $\mathrm{pCBT}$ constructs were used in transient GFP-agroinfiltration assays for identifying LCV-encoded VSRs.

General methods for the manipulation of nucleic acids are as described by Sambrook and Russell (2001). All cloned PCRamplified DNAs were analyzed by nucleotide sequencing in both directions to ensure that no spurious mutations were introduced.

Agroinfiltration. Each binary vector plasmid was introduced into A. tumefaciens strain GV3101 by the freeze-thaw method (Weigel and Glazebrook 2006). The transformed A. tumefaciens cultures (each harboring a binary plasmid of interest) were grown overnight in $10 \mathrm{ml}$ of Luria-Bertani broth containing rifampicin $(50 \mu \mathrm{g} / \mathrm{ml})$, kanamycin $(50 \mu \mathrm{g} / \mathrm{ml})$, and acetosyringone $(100 \mu \mathrm{M})$ at $28^{\circ} \mathrm{C}$. Bacteria cultures were collected by centrifugation at $5,000 \mathrm{rpm}$ at room temperature for $5 \mathrm{~min}$, washed once with agroinfiltration medium (10 mM 2-( $N$-morpholino)ethanesulfonic acid- $\mathrm{HCl}[\mathrm{pH}$ 5.85], $10 \mathrm{mM} \mathrm{MgCl}_{2}$, and $100 \mu \mathrm{M}$ acetosyringone), then resuspended in agroinfiltration medium to a cell concentration of $\mathrm{OD}_{600}=1.0$. A suspension of A. tumefaciens culture harboring one of the candidate suppressor constructs was mixed with an equal volume of either (i) an A. tumefaciens culture transformed with the 35S/GFP construct, or (ii) a mixture of two $A$. tumefaciens cultures, one transformed with the 35S/GFP construct and the other transformed with the 35S/dsGFP construct. Following incubation at room temperature for $\sim 3 \mathrm{~h}$, the suspension mixture was infiltrated into fully expanded $N$. benthamiana leaves with a $3-\mathrm{ml}$ syringe without a needle. In experiments aimed at investigating the suppression of systemic silencing, the first and the second true leaves of $\sim 3$ - to 4-week-old $N$. benthamiana plants were infiltrated with the Agrobacterium mixture. Infiltrated plants were grown in a growth chamber maintained at $21^{\circ} \mathrm{C}$ with a $16-\mathrm{h}$ light/8-h dark photoperiod.

Northern blot analysis of GFP mRNA and siRNA. Agroinfiltrated leaf tissues $(\sim 0.5 \mathrm{~g})$ were frozen in liquid nitrogen and macerated into a fine powder with a mortar and pestle. Total nucleic acids were extracted by phenol-chloroform and chloroform extraction following standard procedures. The high molecular weight (HMW) nucleic acids fraction was precipitated by centrifugation in the presence of $0.5 \mathrm{M} \mathrm{NaCl}$ and $10 \%$ polyethylene glycol (PEG) 8000 and resuspended in water. HMW RNA was selected with an equal volume of $4 \mathrm{M} \mathrm{LiCl}$, precipitated by incubation on ice for $2 \mathrm{~h}$, pelleted by centrifugation, and then resuspended in an appropriate volume of RNase-free water. Low molecular weight (LMW) RNA present within the supernatant of the PEG precipitation was precipitated with ethanol following standard procedures (Hamilton and Baulcombe 1999).

Northern blot was used for the analysis of GFP mRNA and GFP siRNA. To analyze GFP mRNA, $0.5 \mu \mathrm{g}$ of HMW RNA denatured by heating in the presence of glyoxal was separated by electrophoresis in a $1 \%$ agarose gel and transferred onto a positively charged nylon membrane (Hybond $\mathrm{N}+$, GE Healthcare, Buckinghamshire, UK) by capillary transfer. To analyze GFP siRNA, LMW RNA, dissolved in $40 \%$ deionized formamide, was heat-denatured, separated by electrophoresis in a $7 \mathrm{M}$ urea/15\% polyacrylamide gel, and electroblotted onto Hybond-N+ membrane. Oligoribonucleotides (21 and $25 \mathrm{nt}$ long), with sequences derived from the GFP coding region
(5'-UCAUAUGAAGCGGCACGACUU-3' and 5' - UCAUAUGAAG CGGCACGACUUCUUC-3' ${ }^{\prime}$, respectively), were custom synthesized (Operon Biotechnologies, Inc.), and 200 pg each was loaded in the polyacrylamide gel to serve as size markers. A digoxigenin (DIG)labeled riboprobe complementary to the GFP mRNA (corresponding to nt 61 to 450 of mGFP5-ER) was made by using the DIG Northern Starter Kit (Roche, Basel, Switzerland). Prehybridization, hybridization, and signal detection were performed according to the manufacturer's instructions, except that prehybridization and hybridization were carried out at $40^{\circ} \mathrm{C}$ for siRNA analysis.

Observation of GFP fluorescence and staining of necrotic leaf tissues. GFP fluorescence in agroinfiltrated $N$. benthamiana plants was observed using a long-wavelength ultraviolet (UV) lamp (Model B-100A, UVP, Upland, CA). Photographs were taken by a digital camera (E-510, Olympus, Tokyo, Japan) equipped with both UV and yellow filters. Images were processed by Adobe Photoshop CS5 software (Adobe Systems, San Jose, CA). Necrosis in agroinfiltrated $N$. benthamiana leaves was visualized by trypan blue staining as described by (Komatsu et al. 2010). Briefly, leaves were boiled for $3 \mathrm{~min}$ in an alcoholic lactophenol (99\% ethanol/ lactophenol, 2:1)-trypan blue $(0.2 \mathrm{mg} / \mathrm{ml})$ solution, left to stain overnight at room temperature, and destained in chloral hydrate solution containing $2.5 \mathrm{~g}$ of chloral hydrate in $1 \mathrm{ml}$ of water.

\section{RESULTS}

Identification of silencing suppressors from LCV-encoded proteins. To identify LCV-encoded VSRs, we tested seven candidate LCV genes (1b, P23, HSP70h, P60, CP, CPm, and P27) and $\mathrm{P} 23-\mathrm{FS}$, an engineered frameshift mutant of P23, for suppressor activity using transient GFP-agroinfiltration patch assays (Johansen and Carrington 2001) (Fig. 1). In these assays, A. tumefaciens harboring a GFP construct, 35S/GFP (for GFP production and for initiating RNA silencing) (Fig. 1), was infiltrated into the leaves of WT $N$. benthamiana plants. Co-infiltration was performed using A. tumefaciens harboring a construct of each of the above LCV genes or P23-FS. Positive and negative controls for suppressor activity were provided by co-infiltration using $A$. tumefaciens harboring a construct expressing TuMV P1/HC-Pro (a well-known suppressor of RNA silencing) (Kasschau et al. 2003) and A. tumefaciens harboring an empty vector, respectively (Fig. 1). The co-infiltrated leaves were observed for suppressor activity 3 days postinfiltration (dpi) by assessing the intensity of GFP fluorescence under UV illumination. Leaf tissues co-infiltrated with the empty vector showed a low level of GFP fluorescence as did leaf tissues co-infiltrated with P23-FS, indicating the onset of local RNA silencing (Fig. 2A, left panel). In contrast, leaf tissues co-infiltrated with the TuMV P1/HC-Pro construct emitted strong GFP fluorescence, indicating the presence of gene silencing suppression activity (Fig. 2A, left panel). Among all the LCV gene constructs tested in this assay (not shown), suppressor activity was observed only in leaf tissues co-infiltrated with the LCV P23 construct (Fig. 2A, left panel). However, this activity appeared to be weaker than that of TuMV P1/HC-Pro as suppression of RNA silencing by P23, gauged by GFP fluorescence, decreased progressively and did not last longer than 7 days (not shown).

To further evaluate and confirm the suppressor activity of P23, we performed northern hybridization analyses of RNA extracted from leaf tissues, agroinfiltrated with the GFP construct and each of the LCV constructs, at 3 dpi. Accumulation of GFP mRNA in tissues co-infiltrated with the P23 construct was more abundant than those co-infiltrated with the P23-FS construct and the empty vector, but less than in tissues co-infiltrated with the TuMV P1/HC-Pro construct (Fig. 2B, left panel), consistent with the intensity of GFP fluorescence observed in the leaves co-infiltrated with these constructs (Fig. 2A, left panel). The accumulation of GFP siRNA was inversely correlated with that of GFP mRNA and was much lower in tissues co-infiltrated with the P23 and the TuMV P1/HC-Pro 
constructs than in tissues co-infiltrated with the empty vector and the P23-FS constructs (Fig. 2B, left panel). Both classes of GFP siRNAs (21 to $22 \mathrm{nt}$ and $24 \mathrm{nt}$ ) were more strongly reduced in the presence of TuMV P1/HC-Pro than of P23. Accumulation of the 21 to $22 \mathrm{nt}$ class of GFP siRNA was greater than that of the $24 \mathrm{nt}$ class of GFP siRNA in the presence of each of these proteins (Fig. 2B, left panel, compare lanes HC-Pro and P23). Collectively, these results indicate that P23 is a functional, albeit weaker, suppressor of local silencing compared with TuMV P1/HC-Pro.

Suppression of silencing induced by dsRNA. Suppression can occur at different steps in the RNA silencing pathway (Jiang et al. 2012). Here, we determined whether or not LCV P23 could suppress RNA silencing in parallel with or downstream of dsRNA production, a quintessential trigger for RNA silencing. WT $N$. benthamiana plants were infiltrated with a mixture of two Agrobacterium cultures - one containing a 35S/GFP construct (for GFP production) and the other containing a 35S/dsGFP construct engineered to produce GFP hairpin dsRNAs (Fig. 1). Co-infiltration was performed with $A$. tumefaciens containing one of the following constructs: P23, P23-FS, TuMV P1/HC-Pro, and empty vector. Under UV illumination, GFP florescence was observed only in tissues co-infiltrated with the P23 or the TuMV P1/HC-Pro constructs but not in tissues co-infiltrated with the P23-FS construct or the empty vector (Fig. 2A, right panel). Tissues co-infiltrated with P23 or TuMV P1/HC-Pro emitted weaker fluorescence in the presence of both $35 \mathrm{~S} / \mathrm{GFP}$ and 35S/dsGFP, than in the presence of only 35S/GFP (compare Figure 2A left and right panels). The inverse correlation in accumulation of GFP mRNA and siRNA in tissues co-infiltrated with P23 or TuMV P1/HC-Pro (along with 35S/GFP and 35S/dsGFP) also mirrored that of tissues co-infiltrated with P23 or TuMV P1/HC-Pro in the presence of only 35S/GFP as described above (compare Figure 2B left and right panels). Because P23 was able to suppress local silencing directly induced by the production of dsRNA, this suggested that P23 inhibited RNA silencing in parallel with or downstream of the production of dsRNA.

Suppression of cell-to-cell movement of RNA silencing. RNA silencing can spread from silenced cells to neighboring cells via short-range cell-to-cell movement but specific VSRs can work to inhibit the spread (Himber et al. 2003; Kalantidis et al. 2008; Molnar et al. 2011). Among the crinivirus VSRs, only SPCSV P22 is known to suppress the cell-to-cell movement of RNA silencing (Kreuze et al. 2005). Therefore, experiments demonstrating the suppression of cell-to-cell movement of RNA silencing, or the lackthereof, by LCV P23 would add to the body of knowledge on the different modes of action of crinivirus VSRs. The experimental strategy involves using GFP-expressing transgenic $N$. benthamiana (line 16c) plants in which the silencing of GFP expression can be induced by agroinfiltration of a GFP construct. Short-range cell-tocell movement of RNA silencing is visualized as a fine dark zone caused by the silencing of GFP production in the tissues surrounding the infiltrated area. However, no dark zone would form when the spread of RNA silencing is inhibited by a VSR (Himber et al. 2003; Kreuze et al. 2005). In this study, leaves of line 16c plants were infiltrated with a mixture of two A. tumefaciens cultures-one harboring a 35S/GFP construct for GFP expression and induction of RNA silencing, and the other harboring one of the following constructs: P23, P23-FS, CP, or CPm. TuMV P1/HC-Pro, known to block silencing that occurs in response to the silencing signal (Kreuze et al. 2005), was used as a positive control, and pCB-Empty as an empty vector negative control. Four to six independent agroinfiltration patch assays for each of the above constructs were administered, using two or three leaves of each of two line $16 \mathrm{c}$ plants per assay. UV light examination of the infiltrated leaves 4 to 5 dpi consistently revealed the presence of fine dark zones surrounding the tissues infiltrated with the P23-FS, CP, and CPm constructs as well as the empty vector, indicating that the silencing signals had undergone short-range cell-to-cell spread out of the infiltrated tissues (Fig. 3). In contrast, no dark zone was observed in all of the P23-infiltrated tissues over the same observation period (4 to 5 dpi) (Fig. 3), and up to $10 \mathrm{dpi}$ for all of the TuMV P1/HC-Proinfiltrated tissues (not shown). Necrosis that developed in the P23infiltrated leaves at 5 dpi restricted our observations of VSR activity to no more than $7 \mathrm{dpi}$, as described below. Altogether, these results, repeated in three independent experiments, provided evidence that P23 abolished the short-range cell-to-cell movement of RNA silencing triggered by ssGFP RNA (35S/GFP) in line 16c plants.

Suppression of systemic movement of RNA silencing. RNA silencing signals can spread systemically and have been shown to be blocked by specific VSRs (Guo and Ding 2002; Hamilton et al. 2002; Palauqui et al. 1997; Silhavy et al. 2002; Voinnet et al. 2000). Not all VSRs that inhibit the cell-to-cell movement of RNA silencing also inhibit the systemic movement of RNA silencing or vice versa (Cañizares et al. 2008; Li et al. 2002; Lu et al. 2004; Segers et al. 2006). Because LCV P23 inhibited cell-to-cell RNA silencing (Fig. 3 ), it was of interest to determine whether it also inhibited systemic
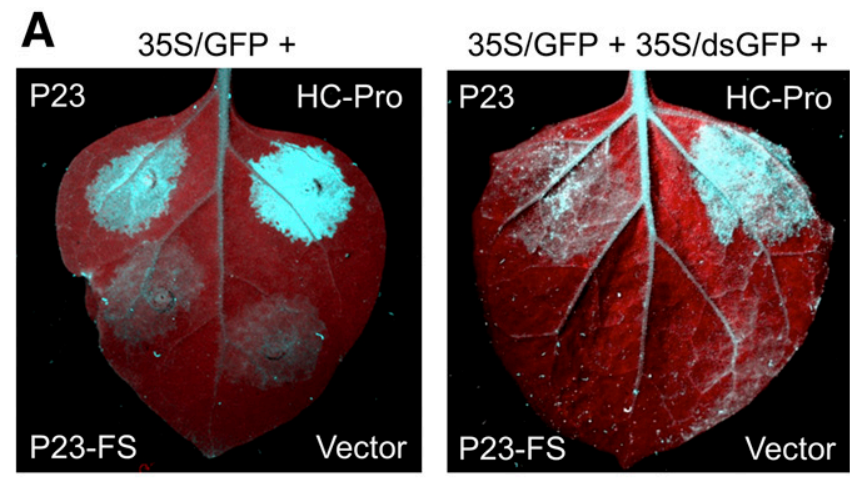

B

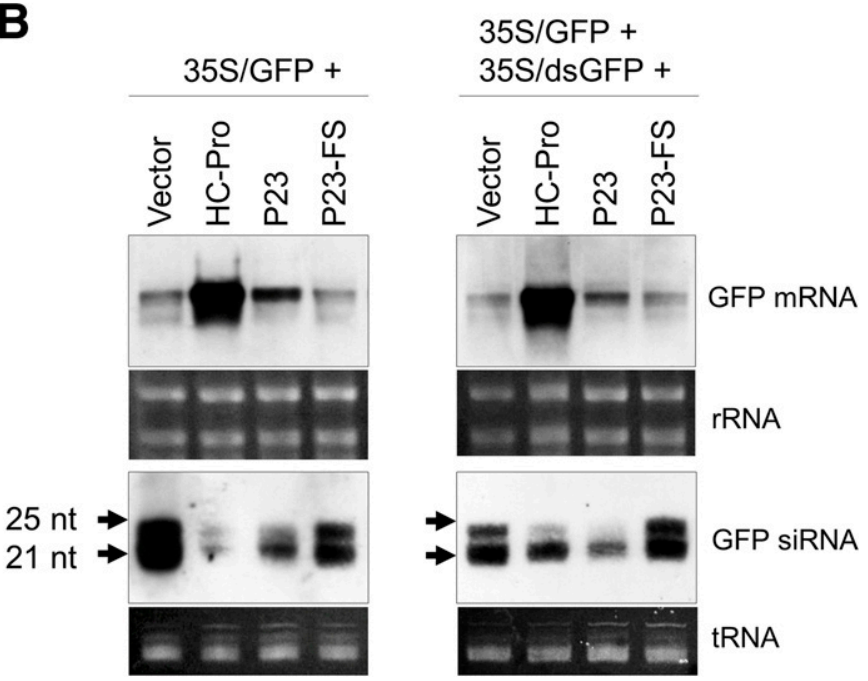

Fig. 2. RNA silencing suppressor activity of Lettuce chlorosis virus (LCV) P23 determined in Agrobacterium co-infiltration assay. A, Wild-type Nicotiana benthamiana plants were infiltrated with Agrobacterium cultures, each harboring a construct expressing one of the following: LCV P23 (P23), a frame shift mutant of LCV P23 (P23-FS), Turnip mosaic virus (TuMV) P1/HC-Pro (HC-Pro), and an empty vector (Vector), together with Agrobacterium harboring a 35S/green fluorescent protein (GFP) construct (left panel) or with two Agrobacterium cultures-one harboring a 35S/GFP construct and one harboring a 35S/dsGFP construct that would generate GFP hairpin dsRNAs (right panel). GFP fluorescence (manifested as green patches) was observed on the abaxial side of the leaves under UV light at 3 days postinfiltration (dpi). The leaf areas that appear red are due to chlorophyll fluorescence. B, Northern hybridization analysis of GFP mRNA (upper panels) and GFP siRNA (lower panels) in the agroinfiltrated tissues obtained from plants treated as in panel A. RNA samples were extracted at 3 dpi. Ethidium bromide-stained rRNA and tRNA are shown as loading controls for mRNA and siRNA, respectively. Positions of the 25- and 21-nt RNA size markers are indicated by arrows. 
RNA silencing. The assay for suppression of systemic movement of RNA silencing was conducted in the same manner, and with the same constructs, as for the assay for suppression of cell-to-cell RNA silencing, with two exceptions: (i) the assay plants were smaller, with three to four true leaves, compared with those used for studying the suppression of cell-to-cell movement of RNA silencing; and, (ii) the systemic leaves of entire GFP transgenic $N$. benthamiana line $16 \mathrm{c}$ plants were examined for GFP fluorescence up to $20 \mathrm{dpi}$.

This assay revealed a trend that was consistent with systemic RNA silencing (in plants infiltrated with P23-FS, CP, CPm, and the empty vector) and its suppression (in plants infiltrated with $\mathrm{P} 23$ and TuMV P1/HC-Pro). In plants infiltrated with P23-FS, CP, CPm, and the empty vector, systemic RNA silencing, seen as a loss of GFP fluorescence in the systemic leaves was observed as early as $7 \mathrm{dpi}$; partial or complete loss of GFP fluorescence in all of the systemic leaves was seen in approximately 30 to 36 of the 48 plants (i.e., up to $75 \%$ ) infiltrated with each of these constructs by 20 dpi (Fig. 4). In plants infiltrated with TuMV P1/HC-Pro, known to exhibit activity consistent with suppression of systemic RNA silencing as determined by leaf patch assays (Kreuze et al. 2005; Tatineni et al. 2012), inhibition of systemic RNA silencing was observed, with a majority of the plants showing GFP fluorescence in all of the systemic leaves for up to $20 \mathrm{dpi}$ (Fig. 4). Only 8 plants out of 48 tested (approximately 17\%) showed a loss of GFP fluorescence by 20 dpi (Fig. 4B). In these plants, the loss of GFP fluorescence was delayed, beginning at $10 \mathrm{dpi}$ instead of $7 \mathrm{dpi}$ as seen in plants co-

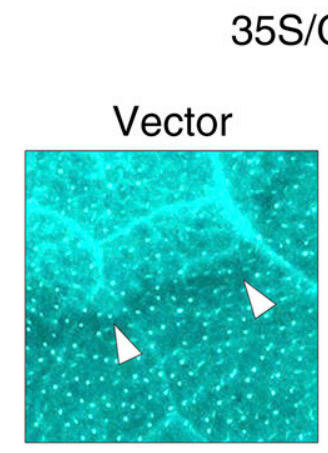

\section{GFP +}

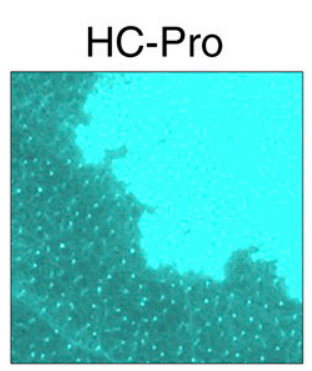

P23

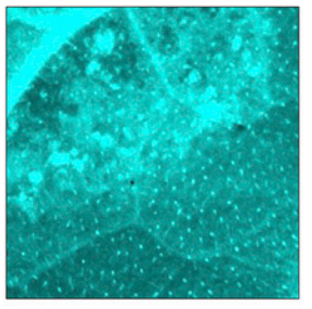

$\mathrm{CP}$

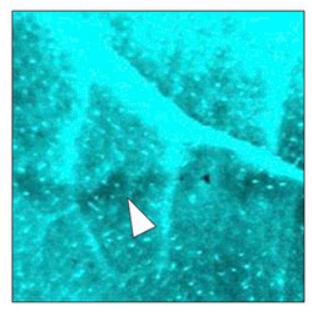

P23-FS

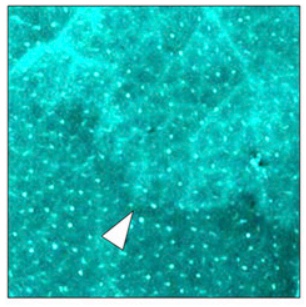

$\mathrm{CPm}$

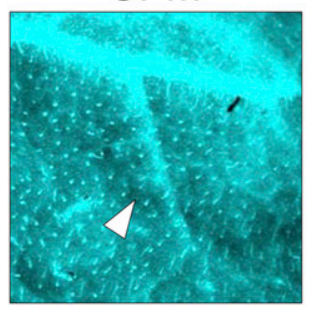

Fig. 3. Inhibition of cell-to-cell movement of RNA silencing by Lettuce chlorosis virus (LCV) P23. Green fluorescent protein (GFP) transgenic $\mathrm{Ni}$ cotiana benthamiana line $16 \mathrm{c}$ plants were agroinfiltrated with a $35 \mathrm{~S} / \mathrm{GFP}$ construct in combination with either an empty vector (Vector) or a construct expressing one of the following: Turnip mosaic virus (TuMV) P1/HC-Pro (HC-Pro), LCV P23 (P23) or its frame-shift mutant (P23-FS), LCV major coat protein $(\mathrm{CP})$, and LCV minor $\mathrm{CP}(\mathrm{CPm})$. Photographs were taken at 5 days postinfiltration. Cell-to-cell movement of silencing signal from the infiltrated patches was visualized as dark zones (arrowheads) surrounding the infiltrated tissues. infiltrated with P23-FS, CP, CPm, and the empty vector (Fig. 4B), and strictly confined to the veins (data not shown). These results were consistent with studies showing the suppression of systemic RNA silencing in line 16c plants agroinfiltrated with GFP constructs in the presence of the P1/HC-Pro of TuMV or Potato virus $Y$ (Hamilton et al. 2002; Tatineni et al. 2012). A trend toward the suppression of systemic silencing by LCV P23 was also observed in most of the plants tested (Fig. 4). The onset of RNA silencing in the systemic leaves, seen in approximately $19 \%$ ( 9 out of 48 ) of the plants by $20 \mathrm{dpi}$, was delayed, beginning at $15 \mathrm{dpi}$ (Fig. 4B), and was also confined only to the veins (data not shown). Taken together, these results suggest that P23 functions as a suppressor of systemic RNA silencing, with an efficiency that is comparable to that of TuMV P1/HC-Pro.

Induction of necrosis in LCV P23-infiltrated leaves. In the course of our experiments, we observed necrosis in the local leaves of both WT $N$. benthamiana and line 16c plants agroinfiltrated with $35 \mathrm{~S} / \mathrm{GFP}$ or $35 \mathrm{~S} / \mathrm{GFP}+35 \mathrm{~S} / \mathrm{dsGFP}$, respectively, when the leaves were co-infiltrated with the LCV P23 construct (data not shown). The necrosis was visible at $21^{\circ} \mathrm{C}$, the temperature at which all of the agroinfiltrated plants used in this study were maintained. A representative image of a line $16 \mathrm{c}$ plant with a $35 \mathrm{~S} / \mathrm{GFP}$ - and $\mathrm{P} 23$-infiltrated leaf undergoing necrosis is shown in Figure 5A (top panel). In contrast, grown under the same temperature condition, plants co-infiltrated with the other constructs (P23-FS, CP, CPm, empty vector, and TuMV P1/HC-Pro) did not develop necrosis in the local leaves. A representative image of a line 16c plant with a $35 \mathrm{~S} /$
A

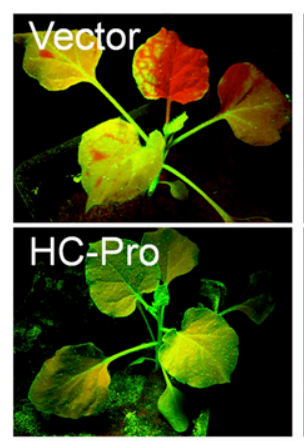

B

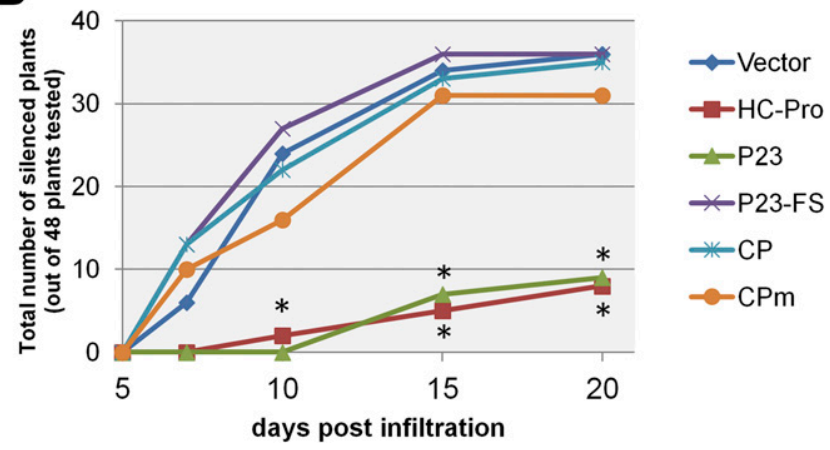

Fig. 4. Inhibition of systemic movement of RNA silencing by Lettuce chlorosis virus (LCV) P23. A, The first and second true leaves of green fluorescent protein (GFP) transgenic Nicotiana benthamiana line 16c plants were agroinfiltrated with a $35 \mathrm{~S} / \mathrm{GFP}$ construct in combination with either an empty vector (Vector) or a construct expressing one of the following: Turnip mosaic virus (TuMV) P1/HC-Pro (HC-Pro), LCV P23 (P23) or its frame shift mutant (P23-FS), LCV major coat protein (CP), and LCV minor CP (CPm). Systemic silencing of the GFP gene in the noninfiltrated upper leaves was visible as red autofluorescence of chlorophyll under UV light irradiation. Photographs were taken at 14 days postinfiltration (dpi). B, Line 16c plants agroinfiltrated as in panel A were monitored for the onset of systemic silencing at 5, 10, 15, and 20 dpi. The number of silenced plants in total of 48 plants tested (three separate experiments with 16 plants each) is shown. The asterisks indicate that systemic silencing was confined only to the veins in these plants. 
GFP- and P23-FS-infiltrated leaf that is free of necrosis is shown in Figure 5A (bottom panel). To investigate the phenomenon more precisely, we agroinfiltrated the leaf tissues of WT $N$. benthamiana plants with the P23 construct or one of the other constructs (P23-FS, $\mathrm{CP}$, and empty vector) individually (i.e., not mixing them with the GFP constructs), and maintained the plants at three different temperatures $\left(18,21\right.$, or $\left.27^{\circ} \mathrm{C}\right)$ (Fig. 5B). Necrosis was observed in the P23-infiltrated tissues but not in the tissues infiltrated with P23-FS, LCV CP, or the empty vector (Fig. 5B, top panels). Necrosis formation was confirmed by staining the agroinfiltrated leaves with trypan blue (Fig. 5B, bottom panels). Plants kept at all three temperatures developed necrosis in the P23-infiltrated patches (Fig. 5B). However, the severity of necrosis was lowest at $18^{\circ} \mathrm{C}$ and highest at $27^{\circ} \mathrm{C}$ (Fig. 5B), suggesting that the LCV P23-triggered necrosis was enhanced at elevated temperatures.

\section{DISCUSSION}

Viruses in the family Closteroviridae are classified into four genera (Closterovirus, Crinivirus, Ampelovirus, and Velarivirus), each embodied by its own unique biology, but all with large and complex genomes (Martelli and Candresse 2014). A number of viruses in this family have acquired the distinction of being the very few that encode multiple VSRs, including the previously described P22 and RNase III of SPCSV; and P22, CP, and CPm of ToCV (Cañizares et al. 2008; Kreuze et al. 2005). Additional examples include the CP, P20, and P23 of Citrus tristeza virus (CTV; genus Closterovirus) ( $\mathrm{Lu}$ et al. 2004). Yet, not all viruses in this family encode multiple VSRs, for example, Beet yellows virus (genus Closterovirus) has one VSR (P21) (Reed et al. 2003). Similarly, Kataya et al. (2009) identified the RNA 1-encoded P25 of CYSDV as the only one, among four CYSDV RNA 1-encoded proteins tested, to exhibit VSR activity; although no CYSDV RNA 2-encoded proteins were screened in that study. Here, we tested multiple, but not all, coding sequences from both RNAs 1 and 2 of LCV and determined that LCV P23 is a functional suppressor of RNA silencing.

Although P23 was expressed transiently under the control of the CaMV 35S promoter, this was sufficient to reveal its role as a VSR in the co-infiltration leaf patch assays for determining the suppression against local, cell-to-cell and systemic silencing. By contrast, results from the same three assays clearly showed that LCV CP and CPm lacked VSR activity. The suppression of local silencing also was not observed for 1b, HSP70h, P60, and P27. However, since these proteins have not been tested for suppression against cell-to-cell and systemic silencing, the possibility that they may contribute to suppression at these levels cannot yet be ruled out completely. Evidence in support of this possibility is provided by experiments demonstrating that intracellular (local) and intercellular (cell-tocell and systemic) silencing are each targeted by a CTV encoded protein (P23 and P20), respectively, while suppression of silencing at both levels is mediated by the CTV CP (Lu et al. 2004). Nevertheless, the lack of VSR activity does not necessarily imply that LCV CP, CPm, 1b, HSP70h, P60, and P27 do not contribute to protection against antiviral defense in other ways; for example, virus-encoded proteins can interact with and protect viral RNA by forming ribonucleoprotein complexes or participate in essential viral functions such as replication and movement to ensure a sustained level of inoculum required for systemic infection (Kim et al. 2007; Liang et al. 2002; Qu and Morris 2002; Scholthof 2006; Taliansky et al. 2003). Another possibility is that the other LCV proteins may possess VSR activity, but they are weak in comparison with that of LCV P23. To address this possibility, stronger and longer lasting expression of candidate LCV proteins could be achieved by using a viral expression vector, such as Potato virus $X$ (PVX), to express these proteins in planta (Cañizares et al. 2008). Had no VSR been identified in our testing of the individual candidate LCV proteins, we would have tested a combination of these proteins delivered by either agroinoculation or PVX inoculation. However, as is now demonstrated, with the identification of P23 as a VSR, its characterization became the focal point of this study.

Even with LCV P23 being newly added to the list of crinivirus VSRs, it is still not possible to establish any clear indicators/patterns that can predict which crinivirus protein might exhibit VSR activity or how many VSRs a crinivirus might encode. This is challenging, in part, due to the low or lack of amino acid sequence homology among many of the proteins encoded by different criniviruses (Dolja et al. 2006). For example, LCV P23 shares with two of its closest homologous proteins, the Bean yellow disorder virus encoded P26 and ToCV P22 (a known suppressor of local silencing), only 45 and $41 \%$ sequence similarity, respectively (Cañizares et al. 2008; Salem et al. 2009), while CYSDV P25 does not show any sequence homology with other crinivirus encoded proteins (Aguilar et al. 2003).

It is clear from the co-infiltration leaf patch assays performed on WT $N$. benthamiana plants (Fig. 2) that LCV P23 suppressed
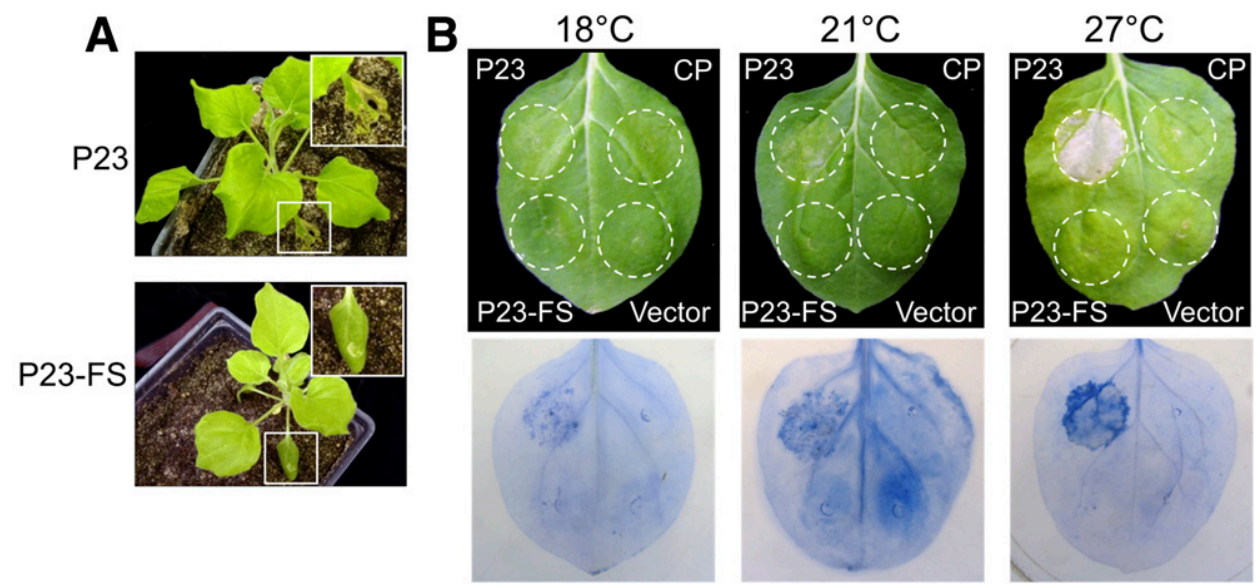

Fig. 5. Temperature-dependent necrosis induction by Lettuce chlorosis virus (LCV) P23. A, Top panel: a green fluorescent protein (GFP) transgenic Nicotiana benthamiana 16c line plant agroinfiltrated with the LCV P23construct (P23) in the presence of 35S/GFP (viewed under visible light) 21 days postinfiltration (dpi), with the infiltrated leaf showing necrotic symptoms (insets). Bottom panel: a GFP transgenic N. benthamiana 16c line plant agroinfiltrated with the P23 frame shift-construct (P23-FS) in the presence of 35S/GFP (viewed under visible light) 21 dpi, with mechanical (infiltration) damage, but no necrosis, in the infiltrated leaf (insets). The plants in the top and the bottom panels were incubated at $21^{\circ} \mathrm{C}$ throughout the course of the analysis. B, Suspensions of Agrobacterium tumefaciens $\left(\mathrm{OD}_{600}=1.0\right)$ each harboring a construct expressing: LCV P23 (P23), its frame shift mutant (P23-FS), the LCV major coat protein (CP) or an empty vector (Vector) were infiltrated into fully expanded nontransgenic $N$. benthamiana leaves. Top panels: the infiltrated plants were kept at 18,21 , or $27^{\circ} \mathrm{C}$ and representative images of the infiltrated leaves are shown. Bottom panels: leaves from the top panels were stained with trypan blue and decolorized with chloral hydrate at $5 \mathrm{dpi}$ for the visualization of dead cells. 
RNA silencing triggered locally by both ss (sense) and ds (hairpin) GFP RNA. For ssGFP RNA (produced transiently as GFP mRNA following agroinfiltration) to target itself for silencing, it would have to either serve as a template for aberrant RNA production, or form dsRNA-like secondary structures within the GFP mRNA (Baulcombe 2004; Luo and Chen 2007; Vazquez et al. 2010). Both forms of RNAs are likely weaker/slower triggers of RNA silencing compared with dsRNAs produced by self-complementary hairpin RNAs (Bologna and Voinnet 2014; Brodersen and Voinnet 2006; Johansen and Carrington 2001; Parent et al. 2012). This may explain why weaker GFP fluorescence was observed in leaf patches agroinfiltrated with both $35 \mathrm{~S} / \mathrm{GFP}$ and $35 \mathrm{~S} / \mathrm{dsGFP}$ than with $35 \mathrm{~S} /$ GFP alone, whether suppression of RNA silencing was mediated by P23 or TuMV P1/HC-Pro (Fig. 2). Because P23 suppressed local silencing induced by dsRNAs, it probably targeted dsRNA or steps downstream of dsRNA production. The suppression activity of P23, like that of TuMV P1/HC-Pro, also demonstrated by the corresponding reduction of GFP-specific siRNA accumulation (Fig. 2), suggested that P23 either interfered with the accumulation or enhanced the degradation of GFP-specific siRNAs. Because P23 reduced GFPspecific siRNA accumulation without abolishing it, this suggested that, like TEV P1/HC-Pro (Anandalakshmi et al. 1998; Lakatos et al. 2006), P23 might also target downstream of siRNA biogenesis. Furthermore, because no conserved RNA binding domain could be identified in P23 using the NCBI conserved domain search or other motif search engines (data not shown), this suggested that its suppression mechanism might not involve the binding or sequestration of siRNAs, unlike in the case of P19, the VSR of Tomato bushy stunt virus (TBSV) (Lakatos et al. 2006; Silhavy et al. 2002).

Another feature of the LCV P23-mediated suppression of local silencing is that it is short-lived (not lasting longer than $7 \mathrm{dpi}$ ) compared with that mediated by other VSRs, for example TuMV P1/HC-Pro (lasting over $10 \mathrm{dpi}$, as seen in this and other studies) (Tatineni et al. 2012), ToCV P22 (>30 dpi) (Cañizares et al. 2008), and TBSV P19 (>12 dpi). The basis underlying this difference between LCV P23 and the other VSRs is not at all clear, but it may be a reflection of the differences in protein stability and in the host range of the viruses that express these VSRs, or differences among the VSRs in the targeting of host factors in the RNA/antiviral silencing pathways (Ahn et al. 2011; Carbonell et al. 2012; Huang et al. 2015).

The ss and dsGFP RNAs, or a combination of both, have been used for the co-infiltration of line 16c plants to assess different VSRs for their ability to block the movement of RNA silencing signals (referred to as cell-to-cell silencing or systemic silencing hereinafter for simplicity) and different outcomes have been observed. Kreuze et al. (2005) showed that dsGFP RNA-triggered cell-to-cell and systemic silencing were inhibited by SPCSV P22, while Cañizares et al. (2008) found that neither cell-to-cell nor systemic silencing induced by ssGFP RNA could be blocked by ToCV P22. Our observation that LCV P23 blocked both the short range cell-to-cell and the systemic movement of RNA silencing signals triggered by ssGFP RNA in line16c plants (Figs. 3 and 4) thus adds further nuances to these differences. Studies that have investigated the role of TBSV P19 in suppression of RNA silencing indicated that it inhibits both ssGFP RNA-induced cell-to-cell and systemic silencing (Hamilton et al. 2002; Himber et al. 2003; Qiu et al. 2002). P19 also suppresses virus-targeted RNA silencing induced upon TBSV infection, and it is necessary for efficient systemic infection and symptom development in $N$. benthamiana (Qiu et al. 2002; Qu and Morris 2002) (reviewed by Scholthof 2006). By contrast, we have no knowledge of the P23-mediated suppression activity against virus-induced and virus-targeted silencing, and its role in systemic infection. However, we know from our previous work that the LCV subgenomic RNA that enables the expression of $\mathrm{P} 23$ is produced in abundance in protoplasts and at the whole plant level, and accumulates in cells rapidly during LCV infection (Mongkolsiriwattana et al. 2011; Salem et al. 2009). This rapid and high level accumulation of P23 is reminiscent of the high titer production of TBSV P19 important for TBSV pathogenicity (Scholthof et al. 1999). Thus, knowledge of the mode of action of LCV P23 in the context of virus infection will provide insights for understanding the infection and symptomatology of LCV and other criniviruses.

An interesting finding in this study was the observation that local leaves of line 16c plants transiently expressing LCV P23 developed necrosis (Fig. 5). A similar phenomenon has been observed in other VSR-plant interactions as well. For example, P19 of tombusviruses, P6 of CaMV, and the $126 \mathrm{~K}$ replication protein of tobamoviruses are suppressors of RNA silencing and also function as inducers of hypersensitive response (HR)-like necrosis (Angel and Schoelz 2013; Ding et al. 2004; Les Erickson et al. 1999; Király et al. 1999; Kubota et al. 2003; Love et al. 2007; Qiu et al. 2002; Scholthof et al. 1995; Silhavy et al. 2002; Voinnet et al. 1999). The Turnip yellows virus (genus Polerovirus) P0 and SPCSV P22 expressed transiently in plants also induce HR in the local leaves (Kreuze et al. 2005; Wang et al. 2015). Furthermore, systemic necrosis develops in plants challenged by PVX expressing either SPCSV P22 or ToCV P22 (Cañizares et al. 2008; Kreuze et al. 2005), although P25, a VSR encoded by PVX, triggers HR-like response in local tissues of agroinfiltrated $N$. benthamiana plants, and it also causes necrotic mottling when expressed from a heterologous vector, Plum pox virus (Aguilar et al. 2015).

What is really unique about the local necrosis induced by the transient expression of LCV P23 is that it increases in severity rapidly (within 5 dpi) with increasing incubation temperatures (Fig. 5), an observation that has never before been reported for the VSRs of any of the other criniviruses. Interestingly, although necrosis is also induced by tombusvirus P19, CaMV P6, the TMV $126 \mathrm{~K}$ protein, and Alternanthera mosaic virus with an efficient VSR, TGB1 $1_{\mathrm{L}(88)}$, the increase in necrosis severity is enhanced at lower temperatures (Király et al. 1999; Lim et al. 2010; Samuel 1931; Szittya et al. 2003). To our knowledge, LCV-infected $N$. benthamiana plants maintained under greenhouse conditions do not develop macroscopic (observable by eye) local or systemic necrosis. However, since LCV is a phloem-restricted virus, we have not ruled out the possibility of necrosis occurring at the microscopic level in the phloem tissues of LCV-infected plants, as has been previously reported for the crinivirus Cucumber yellows virus (Beet pseudo yellows virus) (Yamashita et al. 1979). It is also possible that the necrosis we observed in P23 agroinfiltrated leaves was caused by the transient overexpression of $\mathrm{P} 23$ and that in the context of a virus infection, the expression of P23, although high (Mongkolsiriwattana et al. 2011; Salem et al. 2009), is at levels that do not induce stresses that result in necrosis. In protoplasts inoculated with the in vitro produced transcripts of LCV RNAs 1 and 2, the P23 sgRNA accumulates abundantly but reaches a maximum at $48 \mathrm{~h}$ postinoculation (hpi), whereas genomic RNA 1 continues to accumulate until the final sampling time of $96 \mathrm{hpi}$, suggesting that the expression of P23 is regulated up to a certain level (Mongkolsiriwattana et al. 2011). The VSRs of some viruses are known to function as virulent effectors (giving rise to HR in resistant hosts) (de Ronde et al. 2013; Li et al. 2012; Wang et al. 2012; Zvereva and Pooggin 2012); however, we do not know if the local necrosis induced by LCV P23 was the result of resistance gene-mediated HR. At elevated temperatures, RNA silencing is known to be effective in strengthening plant host defenses against viruses (as evidenced by an increase in viral siRNA production) (Szittya and Burgyán 2013; Szittya et al. 2003). This may work in concert with and enhance host-VSR interaction (in ways that we still do not understand), leading to the rapid triggering of cell death in the host. In turn, the induced cell death may block movement of the systemic silencing signal, thereby effectively preventing systemic silencing. It is possible that the relatively robust reduction in systemic silencing, as a direct effect of the VSR activity of LCV P23 (Fig. 4), could have been enhanced by this phenomenon. Future studies aimed at dissecting the VSR mechanisms of LCV P23 should provide the answers to some of the issues discussed here. 


\section{ACKNOWLEDGMENTS}

We thank A. Chen and C. Mongkolsiriwattana for technical assistance. This work was supported by funds from the U.S. Department of Agriculture National Institute of Food and Agriculture Hatch project (225919) and, in part, by a grant (1146797) from the National Science Foundation awarded to J. C. K. Ng. K. Kubota was a recipient of the Long-Term Fellowship for Overseas Studies award provided by the National Agriculture and Food Research Organization.

\section{LITERATURE CITED}

Aguilar, E., Almendral, D., Allende, L., Pacheco, R., Chung, B. N., Canto, T., and Tenllado, F. 2015. The P25 protein of Potato virus X (PVX) is the main pathogenicity determinant responsible for systemic necrosis in PVX-associated synergisms. J. Virol. 89:2090-2103.

Aguilar, J. M., Franco, M., Marco, C. F., Berdiales, B., Rodriguez-Cerezo, E., Truniger, V., and Aranda, M. A. 2003. Further variability within the genus Crinivirus, as revealed by determination of the complete RNA genome sequence of Cucurbit yellow stunting disorder virus. J. Gen. Virol. 84:2555-2564.

Ahn, J. W., Lee, J. S., Davarpanah, S. J., Jeon, J. H., Park, Y. I., Liu, J. R., and Jeong, W. J. 2011. Host-dependent suppression of RNA silencing mediated by the viral suppressor p19 in potato. Planta 234:1065-1072.

Anandalakshmi, R., Pruss, G. J., Ge, X., Marathe, R., Mallory, A. C., Smith, T. H., and Vance, V. B. 1998. A viral suppressor of gene silencing in plants. Proc. Natl. Acad. Sci. USA 95:13079-13084.

Angel, C. A., and Schoelz, J. E. 2013. A survey of resistance to Tomato bushy stunt virus in the genus Nicotiana reveals that the hypersensitive response is triggered by one of three different viral proteins. Mol. Plant-Microbe Interact. 26:240-248.

Baulcombe, D. 2004. RNA silencing in plants. Nature 431:356-363.

Baumberger, N., and Baulcombe, D. C. 2005. Arabidopsis ARGONAUTE1 is an RNA slicer that selectively recruits microRNAs and short interfering RNAs. Proc. Natl. Acad. Sci. USA 102:11928-11933.

Bologna, N. G., and Voinnet, O. 2014. The diversity, biogenesis, and activities of endogenous silencing small RNAs in Arabidopsis. Annu. Rev. Plant Biol. 65:473-503.

Brigneti, G., Voinnet, O., Li, W. X., Ji, L. H., Ding, S. W., and Baulcombe, D. C. 1998. Viral pathogenicity determinants are suppressors of transgene silencing in Nicotiana benthamiana. EMBO J. 17:6739-6746.

Brodersen, P., and Voinnet, O. 2006. The diversity of RNA silencing pathways in plants. Trends Genet. 22:268-280.

Burgyán, J., and Havelda, Z. 2011. Viral suppressors of RNA silencing. Trends Plant Sci. 16:265-272.

Cañizares, M. C., Lozano-Duran, R., Canto, T., Bejarano, E. R., Bisaro, D. M., Navas-Castillo, J., and Moriones, E. 2013. Effects of the crinivirus coat protein-interacting plant protein SAHH on post-transcriptional RNA silencing and its suppression. Mol. Plant-Microbe Interact. 26:1004-1015.

Cañizares, M. C., Navas-Castillo, J., and Moriones, E. 2008. Multiple suppressors of RNA silencing encoded by both genomic RNAs of the crinivirus, Tomato chlorosis virus. Virology 379:168-174.

Carbonell, A., Dujovny, G., Garcia, J. A., and Valli, A. 2012. The Cucumber vein yellowing virus silencing suppressor $\mathrm{P} 1 \mathrm{~b}$ can functionally replace HCPro in Plum pox virus infection in a host-specific manner. Mol. PlantMicrobe Interact. 25:151-164.

Chen, A. Y., Walker, G. P., Carter, D., and Ng, J. C. K. 2011. A virus capsid component mediates virion retention and transmission by its insect vector. Proc. Natl. Acad. Sci. USA 108:16777-16782.

Chen, A. Y. S., Pavitrin, A., and Ng, J. C. K. 2012. Agroinoculation of the cloned infectious cDNAs of Lettuce chlorosis virus (LCV) to plants results in systemic plant infection and the production of biologically active LCV virions. Virus Res. 169:310-315.

Cuellar, W. J., Kreuze, J. F., Rajamaki, M. L., Cruzado, K. R., Untiveros, M., and Valkonen, J. P. T. 2009. Elimination of antiviral defense by viral RNase III. Proc. Natl. Acad. Sci. USA 106:10354-10358.

De Barro, P. J., Liu, S. S., Boykin, L. M., and Dinsdale, A. B. 2011. Bemisia tabaci: A statement of species status. Annu. Rev. Entomol. 56:1-19.

de Ronde, D., Butterbach, P., Lohuis, D., Hedil, M., van Lent, J. W., and Kormelink, R. 2013. Tsw gene-based resistance is triggered by a functional RNA silencing suppressor protein of the Tomato spotted wilt virus. Mol. Plant Pathol. 14:405-415.

Dellaporta, S. L., Wood, J., and Hicks, J. R. 1983. A plant DNA minipreparation: Version II. Plant Mol. Biol. Rep. 1:19-21.

Diaz-Pendon, J. A., and Ding, S. W. 2008. Direct and indirect roles of viral suppressors of RNA silencing in pathogenesis. Annu. Rev. Phytopathol. 46: 303-326.

Ding, S. W., and Voinnet, O. 2007. Antiviral immunity directed by small RNAs. Cell 130:413-426.
Ding, X. S., Liu, J., Cheng, N. H., Folimonov, A., Hou, Y. M., Bao, Y., Katagi, C., Carter, S. A., and Nelson, R. S. 2004. The Tobacco mosaic virus 126-kDa protein associated with virus replication and movement suppresses RNA silencing. Mol. Plant-Microbe Interact. 17:583-592.

Dolja, V. V., Kreuze, J. F., and Valkonen, J. P. T. 2006. Comparative and functional genomics of closteroviruses. Virus Res. 117:38-51.

Duffus, J. E., Liu, H. Y., Wisler, G. C., and Li, R. H. 1996. Lettuce chlorosis virus -A new whitefly-transmitted closterovirus. Eur. J. Plant Pathol. 102: 591-596.

Guo, H. S., and Ding, S. W. 2002. A viral protein inhibits the long range signaling activity of the gene silencing signal. EMBO J. 21:398-407.

Hamilton, A., Voinnet, O., Chappell, L., and Baulcombe, D. 2002. Two classes of short interfering RNA in RNA silencing. EMBO J. 21:4671-4679. (Corrigendum published in 2015). EMBO J. 34:2590.

Hamilton, A. J., and Baulcombe, D. C. 1999. A species of small antisense RNA in posttranscriptional gene silencing in plants. Science 286:950-952.

Himber, C., Dunoyer, P., Moissiard, G., Ritzenthaler, C., and Voinnet, O. 2003. Transitivity-dependent and -independent cell-to-cell movement of RNA silencing. EMBO J. 22:4523-4533.

Huang, C. H., Hsiao, W. R., Huang, C. W., Chen, K. C., Lin, S. S., Chen, T. C., Raja, J. A., Wu, H. W., and Yeh, S. D. 2015. Two novel motifs of Watermelon silver mottle virus NSs protein are responsible for RNA silencing suppression and pathogenicity. PLoS One 10:e126161.

Jiang, L., Wei, C. H., and Li, Y. 2012. Viral suppression of RNA silencing. Sci. China Life Sci. 55:109-118.

Johansen, L. K., and Carrington, J. C. 2001. Silencing on the spot. Induction and suppression of RNA silencing in the Agrobacterium-mediated transient expression system. Plant Physiol. 126:930-938.

Kalantidis, K., Schumacher, H. T., Alexiadis, T., and Helm, J. M. 2008. RNA silencing movement in plants. Biol. Cell 100:13-26.

Karasev, A. V. 2000. Genetic diversity and evolution of closteroviruses. Annu. Rev. Phytopathol. 38:293-324.

Kasschau, K. D., and Carrington, J. C. 1998. A counterdefensive strategy of plant viruses: Suppression of posttranscriptional gene silencing. Cell 95:461-470.

Kasschau, K. D., Xie, Z. X., Allen, E., Llave, C., Chapman, E. J., Krizan, K. A., and Carrington, J. C. 2003. P1/HC-Pro, a viral suppressor of RNA silencing, interferes with Arabidopsis development and miRNA function. Dev. Cell 4:205-217.

Kataya, A. R. A., Suliman, M. N. S., Kalantidis, K., and Livieratos, I. C. 2009. Cucurbit yellow stunting disorder virus p25 is a suppressor of posttranscriptional gene silencing. Virus Res. 145:48-53.

Kim, S. H., Macfarlane, S., Kalinina, N. O., Rakitina, D. V., Ryabov, E. V., Gillespie, T., Haupt, S., Brown, J. W., and Taliansky, M. 2007. Interaction of a plant virus-encoded protein with the major nucleolar protein fibrillarin is required for systemic virus infection. Proc. Natl. Acad. Sci. USA 104: 11115-11120.

Király, L., Cole, A. B., Bourque, J. E., and Schoelz, J. E. 1999. Systemic cell death is elicited by the interaction of a single gene in Nicotiana clevelandii and gene VI of Cauliflower mosaic virus. Mol. Plant-Microbe Interact. 12:919-925.

Kiss, Z. A., Medina, V., and Falk, B. W. 2013. Crinivirus replication and host interactions. Front. Microbiol. 4:99.

Komatsu, K., Hashimoto, M., Ozeki, J., Yamaji, Y., Maejima, K., Senshu, H., Himeno, M., Okano, Y., Kagiwada, S., and Namba, S. 2010. Viral-induced systemic necrosis in plants involves both programmed cell death and the inhibition of viral multiplication, which are regulated by independent pathways. Mol. Plant-Microbe Interact. 23:283-293.

Kreuze, J. F., Savenkov, E. I., Cuellar, W., Li, X. D., and Valkonen, J. P. T. 2005. Viral class 1 RNase III involved in suppression of RNA silencing. J. Virol. 79:7227-7238.

Kubota, K., Tsuda, S., Tamai, A., and Meshi, T. 2003. Tomato mosaic virus replication protein suppresses virus-targeted posttranscriptional gene silencing. J. Virol. 77:11016-11026.

Lakatos, L., Csorba, T., Pantaleo, V., Chapman, E. J., Carrington, J. C., Liu, Y. P., Dolja, V. V., Calvino, L. F., Lopez-Moya, J. J., and Burgyán, J. 2006. Small RNA binding is a common strategy to suppress RNA silencing by several viral suppressors. EMBO J. 25:2768-2780.

Les Erickson, F., Holzberg, S., Calderon-Urrea, A., Handley, V., Axtell, M., Corr, C., and Baker, B. 1999. The helicase domain of the TMV replicase proteins induces the $N$-mediated defence response in tobacco. Plant J. 18:67-75.

Li, F., Pignatta, D., Bendix, C., Brunkard, J. O., Cohn, M. M., Tung, J., Sun, H. Y., Kumar, P., and Baker, B. 2012. MicroRNA regulation of plant innate immune receptors. Proc. Natl. Acad. Sci. USA 109:1790-1795.

Li, H. W., Li, W. X., and Ding, S. W. 2002. Induction and suppression of RNA silencing by an animal virus. Science 296:1319-1321.

Liang, X. Z., Lucy, A. P., Ding, S. W., and Wong, S. M. 2002. The p23 protein of Hibiscus chlorotic ringspot virus is indispensable for host-specific replication. J. Virol. 76:12312-12319.

Lim, H. S., Vaira, A. M., Reinsel, M. D., Baer, H., Bailey, B. A., Domier, L. L., and Hammond, J. 2010. Pathogenicity of Alternanthera mosaic virus is 
affected by determinants in RNA-dependent RNA polymerase and by reduced efficacy of silencing suppression in a movement-competent TGB1. J. Gen. Virol. 91:277-287.

Liu, J. D., Carmell, M. A., Rivas, F. V., Marsden, C. G., Thomson, J. M., Song, J. J., Hammond, S. M., Joshua-Tor, L., and Hannon, G. J. 2004. Argonaute 2 is the catalytic engine of mammalian RNAi. Science 305:1437-1441.

Love, A. J., Laird, J., Holt, J., Hamilton, A. J., Sadanandom, A., and Milner, J. J. 2007. Cauliflower mosaic virus protein P6 is a suppressor of RNA silencing. J. Gen. Virol. 88:3439-3444.

Lu, R., Folimonov, A., Shintaku, M., Li, W. X., Falk, B. W., Dawson, W. O., and Ding, S. W. 2004. Three distinct suppressors of RNA silencing encoded by a 20-kb viral RNA genome. Proc. Natl. Acad. Sci. USA 101:15742-15747.

Luo, Z. H., and Chen, Z. X. 2007. Improperly terminated, unpolyadenylated mRNA of sense transgenes is targeted by RDR6-mediated RNA silencing in Arabidopsis. Plant Cell 19:943-958.

Martelli, G. P., and Candresse, T. 2014. Closteroviridae. In: eLS. John Wiley \& Sons Ltd., Chichester, UK.

Meister, G., and Tuschl, T. 2004. Mechanisms of gene silencing by doublestranded RNA. Nature 431:343-349.

Molnar, A., Melnyk, C., and Baulcombe, D. C. 2011. Silencing signals in plants: A long journey for small RNAs. Genome Biol. 12:215.

Mongkolsiriwattana, C., Chen, A. Y. S., and Ng, J. C. K. 2011. Replication of Lettuce chlorosis virus (LCV), a crinivirus in the family Closteroviridae, is accompanied by the production of LCV RNA 1-derived novel RNAs. Virology 420:89-97.

Nagy, P. D., and Pogany, J. 2012. The dependence of viral RNA replication on co-opted host factors. Nat. Rev. Microbiol. 10:137-149.

$\mathrm{Ng}$, J. C. K. 2013. A quantum dot-immunofluorescent labeling method to investigate the interactions between a crinivirus and its whitefly vector. Front. Microbiol. 4:77.

Ng, J. C. K., and Zhou, J. S. 2015. Insect vector-plant virus interactions associated with non-circulative, semi-persistent transmission: Current perspectives and future challenges. Curr. Opin. Virol. 15:48-55.

Palauqui, J. C., Elmayan, T., Pollien, J. M., and Vaucheret, H. 1997. Systemic acquired silencing: Transgene-specific post-transcriptional silencing is transmitted by grafting from silenced stocks to non-silenced scions. EMBO J. 16:4738-4745.

Parent, J. S., de Alba, A. E. M., and Vaucheret, H. 2012. The origin and effect of small RNA signaling in plants. Front. Plant Sci. 3:179.

Pumplin, N., and Voinnet, O. 2013. RNA silencing suppression by plant pathogens: Defence, counter-defence and counter-counter-defence. Nat. Rev. Microbiol. 11:745-760.

Qiu, W., Park, J. W., and Scholthof, H. B. 2002. Tombusvirus P19-mediated suppression of virus-induced gene silencing is controlled by genetic and dosage features that influence pathogenicity. Mol. Plant-Microbe Interact. 15:269-280.

Qu, F., and Morris, T. J. 2002. Efficient infection of Nicotiana benthamiana by Tomato bushy stunt virus is facilitated by the coat protein and maintained by p19 through suppression of gene silencing. Mol. Plant-Microbe Interact. 15: 193-202.

Reed, J. C., Kasschau, K. D., Prokhnevsky, A. I., Gopinath, K., Pogue, G. P., Carrington, J. C., and Dolja, V. V. 2003. Suppressor of RNA silencing encoded by Beet yellows virus. Virology 306:203-209.

Ruiz, M. L., Simon, A., Garcia, M. C., and Janssen, D. 2014. First report of Lettuce chlorosis virus infecting bean in Spain. Plant Dis. 98:857.

Ruiz, M. T., Voinnet, O., and Baulcombe, D. C. 1998. Initiation and maintenance of virus-induced gene silencing. Plant Cell 10:937-946.

Salem, N. M., Chen, A. Y., Tzanetakis, I. E., Mongkolsiriwattana, C., and Ng, J. C. K. 2009. Further complexity of the genus Crinivirus revealed by the complete genome sequence of Lettuce chlorosis virus (LCV) and the similar temporal accumulation of LCV genomic RNAs 1 and 2. Virology 390:45-55.

Sambrook, J., and Russell, D. W. 2001. Molecular Cloning: A Laboratory Manual, 3rd ed. Cold Spring Harbor Laboratory Press, Cold Spring Harbor, NY.

Samuel, G. 1931. Some experiments on inoculating methods with plant viruses, and on local lesions. Ann. Appl. Biol. 18:494-507.
Scholthof, H. B. 2006. The tombusvirus-encoded P19: From irrelevance to elegance. Nat. Rev. Microbiol. 4:405-411.

Scholthof, H. B., Desvoyes, B., Kuecker, J., and Whitehead, E. 1999. Biological activity of two tombusvirus proteins translated from nested genes is influenced by dosage control via context-dependent leaky scanning. Mol. Plant-Microbe Interact. 12:670-679.

Scholthof, H. B., Scholthof, K. B., and Jackson, A. O. 1995. Identification of Tomato bushy stunt virus host-specific symptom determinants by expression of individual genes from a Potato virus $X$ vector. Plant Cell 7:1157-1172.

Schwach, F., Vaistij, F. E., Jones, L., and Baulcombe, D. C. 2005. An RNAdependent RNA polymerase prevents meristem invasion by Potato virus $X$ and is required for the activity but not the production of a systemic silencing signal. Plant Physiol. 138:1842-1852.

Segers, G. C., van Wezel, R., Zhang, X. M., Hong, Y. G., and Nuss, D. L. 2006. Hypovirus papain-like protease p29 suppresses RNA silencing in the natural fungal host and in a heterologous plant system. Eukaryot. Cell 5: 896-904.

Silhavy, D., Molnar, A., Lucioli, A., Szittya, G., Hornyik, C., Tavazza, M., and Burgyán, J. 2002. A viral protein suppresses RNA silencing and binds silencing-generated, 21-to 25-nucleotide double-stranded RNAs. EMBO J. 21:3070-3080.

Szittya, G., and Burgyán, J. 2013. RNA interference-mediated intrinsic antiviral immunity in plants. Pages. B. R. Cullen, ed. Curr. Top. Microbiol. Immunol. 371:153-181.

Szittya, G., Silhavy, D., Molnar, A., Havelda, Z., Lovas, A., Lakatos, L., Banfalvi, Z., and Burgyán, J. 2003. Low temperature inhibits RNA silencing-mediated defence by the control of siRNA generation. EMBO J. 22:633-640.

Taliansky, M., Roberts, I. M., Kalinina, N., Ryabov, E. V., Raj, S. K., Robinson, D. J., and Oparka, K. J. 2003. An umbraviral protein, involved in long-distance RNA movement, binds viral RNA and forms unique, protective ribonucleoprotein complexes. J. Virol. 77:3031-3040.

Tatineni, S., Qu, F., Li, R. H., Morris, T. J., and French, R. 2012. Triticum mosaic poacevirus enlists $\mathrm{P} 1$ rather than HC-Pro to suppress RNA silencing-mediated host defense. Virology 433:104-115.

Vazquez, F., Legrand, S., and Windels, D. 2010. The biosynthetic pathways and biological scopes of plant small RNAs. Trends Plant Sci. 15:337-345.

Voinnet, O. 2005. Induction and suppression of RNA silencing: Insights from viral infections. Nat. Rev. Genet. 6:206-220.

Voinnet, O., Lederer, C., and Baulcombe, D. C. 2000. A viral movement protein prevents spread of the gene silencing signal in Nicotiana benthamiana. Cell 103:157-167.

Voinnet, O., Pinto, Y. M., and Baulcombe, D. C. 1999. Suppression of gene silencing: A general strategy used by diverse DNA and RNA viruses of plants. Proc. Natl. Acad. Sci. USA 96:14147-14152. Correction published in 2015. Proc. Natl. Acad. Sci. USA 112:E14812.

Voinnet, O., Vain, P., Angell, S., and Baulcombe, D. C. 1998. Systemic spread of sequence-specific transgene RNA degradation in plants is initiated by localized introduction of ectopic promoterless DNA. Cell 95:177-187.

Wang, K. D., Empleo, R., Nguyen, T. T. V., Moffett, P., and Sacco, M. A. 2015. Elicitation of hypersensitive responses in Nicotiana glutinosa by the suppressor of RNA silencing protein P0 from poleroviruses. Mol. Plant Pathol. 16:435-448.

Wang, M. B., Masuta, C., Smith, N. A., and Shimura, H. 2012. RNA silencing and plant viral diseases. Mol. Plant-Microbe Interact. 25:1275-1285.

Weigel, D., and Glazebrook, J. 2006. Transformation of Agrobacterium Using the Freeze-Thaw Method. Cold Spring Harbor Protocols. Cold Spring Harbor Laboratory Press, Cold Spring Harbor, NY.

Xiang, C. B., Han, P., Lutziger, I., Wang, K., and Oliver, D. J. 1999. A mini binary vector series for plant transformation. Plant Mol. Biol. 40:711-717.

Yamashita, S., Doi, Y., Yora, K., and Yoshino, M. 1979. Cucumber yellows virus: Its transmission by the greenhouse whitefly, Trialeurodes vaporariorum (Westwood), and the yellowing disease of cucumber and muskmelon caused by the virus. Ann. Phytopathol. Soc. Jpn. 45:484-496.

Zvereva, A. S., and Pooggin, M. M. 2012. Silencing and innate immunity in plant defense against viral and non-viral pathogens. Viruses 4:2578-2597. 